\title{
Language hemispheric dominance analyzed with magnetic resonance DTI: correlation with the Wada test
}

\author{
Juan Delgado-Fernández, MD, ${ }^{1}$ Maria Ángeles García-Pallero, MD, ${ }^{2}$ \\ Rafael Manzanares-Soler, MD, ${ }^{3}$ Pilar Martín-Plasencia, PhD, ${ }^{4}$ Guillermo Blasco, MD, ${ }^{4}$ \\ Natalia Frade-Porto, MD, ${ }^{4}$ Marta Navas-García, MD, ${ }^{4}$ Paloma Pulido, PhD, ${ }^{4}$ Rafael G. Sola, PhD, ${ }^{5,6}$ \\ and Cristina V. Torres, $\mathrm{PhD}^{4}$
}

\begin{abstract}
1'Department of Neurosurgery, University Hospital 12 de Octubre, Madrid; ${ }^{2}$ Department of Neurosurgery, Hospital Universitario Central de Asturias, Asturias; ${ }^{3}$ Department of Radiology and ${ }^{4}$ Department of Neurosurgery, University Hospital La Princesa, Madrid; ' 5 Department of Innovation in Neurosurgery, Universidad Autonoma de Madrid; and ${ }^{6}$ Department of Neurosurgery, Hospital del Rosario, Madrid, Spain
\end{abstract}

\begin{abstract}
OBJECTIVE Language lateralization is a major concern in some patients with pharmacoresistant epilepsy who will face surgery; in these patients, hemispheric dominance testing is essential to avoid further complications. The Wada test is considered the gold standard examination for language localization, but is invasive and requires many human and material resources. Functional MRI and tractography with diffusion tensor imaging (DTI) have demonstrated that they could be useful for locating language in epilepsy surgery, but there is no evidence of the correlation between the Wada test and DTI MRI in language dominance.
\end{abstract}

METHODS The authors performed a retrospective review of patients who underwent a Wada test before epilepsy surgery at their institution from 2012 to 2017. The authors retrospectively analyzed fractional anisotropy (FA), number and length of fibers, and volume of the arcuate fasciculus and uncinate fasciculus, comparing dominant and nondominant hemispheres.

RESULTS Ten patients with temporal lobe epilepsy were reviewed. Statistical analysis showed that the mean FA of the arcuate fasciculus in the dominant hemisphere was higher than in the nondominant hemisphere $(0.369$ vs $0.329, p$ $=0.049$ ). Also, the number of fibers in the arcuate fasciculus was greater in the dominant hemisphere ( 881.5 vs 305.4 , $p=0.003$ ). However, no differences were found in the FA of the uncinate fasciculus or number of fibers between hemispheres. The length of fibers of the uncinate fasciculus was longer in the dominant side (74.4 vs $50.1 \mathrm{~mm}, p=0.05$ ). Volume in both bundles was more prominent in the dominant hemisphere $\left(12.12 \mathrm{vs} 6.48 \mathrm{~cm}^{3}, p=0.004\right.$, in the arcuate fasciculus, and 8.41 vs $4.16 \mathrm{~cm}^{3}, p=0.018$, in the uncinate fasciculus). Finally, these parameters were compared in patients in whom the seizure focus was situated in the dominant hemisphere: FA $(0.37$ vs $0.30, p=0.05)$, number of fibers (114.4 vs 315.6, $p=0.014$ ), and volume (12.58 vs $\left.5.88 \mathrm{~cm}^{3}, p=0.035\right)$ in the arcuate fasciculus were found to be statistically significantly higher in the dominant hemispheres. Linear discriminant analysis of FA, number of fibers, and volume of the arcuate fasciculus showed a correct discrimination in $80 \%$ of patients $(p=0.024)$.

CONCLUSIONS The analysis of the arcuate fasciculus and other tract bundles by DTI could be a useful tool for language location testing in the preoperative study of patients with refractory epilepsy.

https://thejns.org/doi/abs/10.3171/2020.4.JNS20456

KEYWORDS Wada test; MRI; DTI; diffusion tensor imaging; arcuate fasciculus; uncinate fasciculus; fractional anisotropy; hemisphere dominance; epilepsy

$\mathrm{L}$ ANGUAGE is one of the most complex functions of the brain and involves different cortical areas and language based on the anatomical findings of Wernicke and Geschwind described the interconnection of the Broca and Wernicke areas by the arcuate fasciculus. Currently, the dual-stream theory of language includes the dorsal stream, involved in sensorimotor features of the language, and the ventral stream for speech comprenhension. ${ }^{1}$ This model also includes the uncinate fasciculus (among oth-

ABBREVIATIONS $\mathrm{Cl}=$ confidence interval; $\mathrm{DTI}=$ diffusion tensor imaging; $\mathrm{FA}$ = fractional anisotropy; fMRI = functional $\mathrm{MRI}$; $\mathrm{ROI}=$ region of interest.

SUBMITTED February 16, 2020. ACCEPTED April 22, 2020.

INCLUDE WHEN CITING Published online July 24, 2020; DOI: 10.3171/2020.4.JNS20456. 
ers), which connects the inferior longitudinal fasciculus to the inferior frontal area and is one of the main tracts on the ventral stream, connecting both pathways., ${ }^{1,2}$

Language is a lateralized function in most humans: 95\% of right-handed people show left-sided hemispheric localization, while $15 \%$ of left-handed people show rightsided localization. ${ }^{3}$ However, in some cases an atypical language lateralization can be identified. Different studies have demonstrated that in patients with previous lesions in the left hemisphere, language lateralization is influenced. ${ }^{4-7}$ This is the case in epilepsy patients who have demonstrated a high degree of language circuit reorganization, mainly in intractable seizures. ${ }^{8,9}$

In this context, a precise location of the epileptogenic focus is mandatory, as surgery should be tailored to avoid damaging any underlying structures. ${ }^{10}$ Normally, the epilepsy protocol includes scalp EEG, neuropsychological evaluation, MRI, and PET or SPECT, ${ }^{11,12}$ but in other cases it should be extended with stereoEEG and foramen ovale electrodes, or subdural electrodes..$^{13}$ Nevertheless, some patients without good outcomes in epilepsy surgery could benefit from further imaging, such as diffusion tensor imaging (DTI)..$^{14,15}$

DTI has demonstrated its utility in describing the microstructure of white matter tracts and defining fascicules and bundles in preoperative planning. In addition, fractional anisotropy (FA), which describes the degree of anisotropy of a diffusion process, ${ }^{16}$ is a very useful tool that helps us to understand the structural integrity of axons and myelin sheaths. ${ }^{17,18}$

Moreover, there are a large number of studies that have recently demonstrated a correlation between DTI and functional MRI (fMRI), which could help us define language lateralization through DTI, thereby avoiding invasive tests such as the Wada test. ${ }^{8,9,19-22}$ However, the Wada test still remains the gold standard test to determine language lateralization, and if we assume that DTI correlates with Wada test results, that could lead to a possible bias. Moreover, the Wada test and fMRI do not have a perfect correlation. In a meta-analysis, Dym et al. ${ }^{23}$ reviewed 442 patients, comparing fMRI with the Wada test, and showed that sensitivity and specificity of fMRI for atypical language dominance were $83.5 \%$ and $88.1 \%$, respectively.

Nevertheless, although the Wada test remains the only definitive method for defining language dominance, it is an invasive, costly, and unpleasant experience for patients. ${ }^{24}$ Therefore, the objective of our study was to compare our results from a preoperative Wada test to DTI, so DTI could be used for preoperative language lateralization in the future.

\section{Methods}

We performed a retrospective study, reviewing all patients who underwent a Wada test to determine hemispheric dominance for language between 2012 and 2017 in La Princesa Hospital, Madrid. Patient records were reviewed and we selected those with temporal lobe epilepsy who had a complete preoperative protocol study, including clinical history and examination, scalp EEG, preoperative cranial MRI with DTI, intercritical cerebral SPECT, neu- ropsychological study, and intercritical and critical video EEG study. In cases in which epilepsy was secondary to a tumor, SPECT and EEG studies were not performed.

\section{MRI}

MR images of patients were acquired on a 1.5-T GE scanner. Diffusion-weighted imaging was obtained using a single-shot echo-planar imaging sequence with the following parameters: TR $11,000 \mathrm{msec}$, FOV $280 \times 280 \mathrm{~mm}$, matrix size $128 \times 128$, voxel dimensions $1.1 \times 1.1 \times 2.9$ $\mathrm{mm}$, slice thickness $3 \mathrm{~mm}, 25$ noncollinear diffusion directions, with a b-value of $1000 \mathrm{sec} / \mathrm{mm}^{2}$ and 1 additional volume without diffusion weighting $\left(b=0 \mathrm{sec} / \mathrm{mm}^{2}\right)$, and 8 minutes of acquisition time. T1-weighted images were acquired using a 3D MPRAGE sequence, providing isotropic voxels of $1 \times 1 \times 1 \mathrm{~mm}$.

\section{Wada Test}

All patients underwent a Wada test. A diagnostic catheter was introduced through the right femoral artery sheath to obtain a pretest angiogram and to evaluate the cerebral vasculature. Once there was no evidence of any pathological or persisting fetal connections, a 6-Fr catheter was located in the internal carotid artery. Then, a combination of $2 \mathrm{ml}$ of $1 \%$ propofol $(20 \mathrm{mg})$ and etomidate $(10 \mathrm{mg})$ was administrated. Neurological examination was performed preoperatively, at the end of the first minute, and 5 minutes after the injection. The same procedure was repeated in the contralateral side after location of the catheter in the internal carotid artery. Neurological examination assessed motor and sensory function, cranial nerves, and language. Patients were asked to name some objects, to read some sentences, and to recall the names of the objects. The Wada test was considered positive when dysnomia appeared..$^{10,25}$

\section{Fiber Tracking}

Based on previous data, the arcuate fasciculus and uncinate fasciculus tracts were traced bilaterally in all patients' preoperative MR images. White matter tracts of both fascicles were localized using BrainLAB software (iPlan Cranial, version 3.0), placing two regions of interest (ROIs) on a coronal and axial slice for each patient. For the arcuate fasciculus, the first ROI was placed on a slice above the body of the corpus callosum in a group of fibers in an anteroposterior direction running lateral to the projection fibers of the corona radiate, and the second ROI in the superior temporal gyrus. ${ }^{26}$ In the uncinate fasciculus, the initial ROI was placed on a coronal view on the hook of the uncinate fasciculus (a temporomesial structure located below the anterior commissure with a main direction in the z-axis) and the second was drawn anteriorly to the genu of the corpus callosum. ${ }^{27}$ The internal capsule was obtained with an ROI placed in the bulb and a second in the motor area, which we used as a control to check that there were no differences between both hemispheres. These landmarks were used as described previously in patients with temporal lobe epilepsy. ${ }^{15,28}$ In all cases, we tried to standardize the initial and final ROI to obtain the same bundles in all patients, to eliminate a possible bias. 

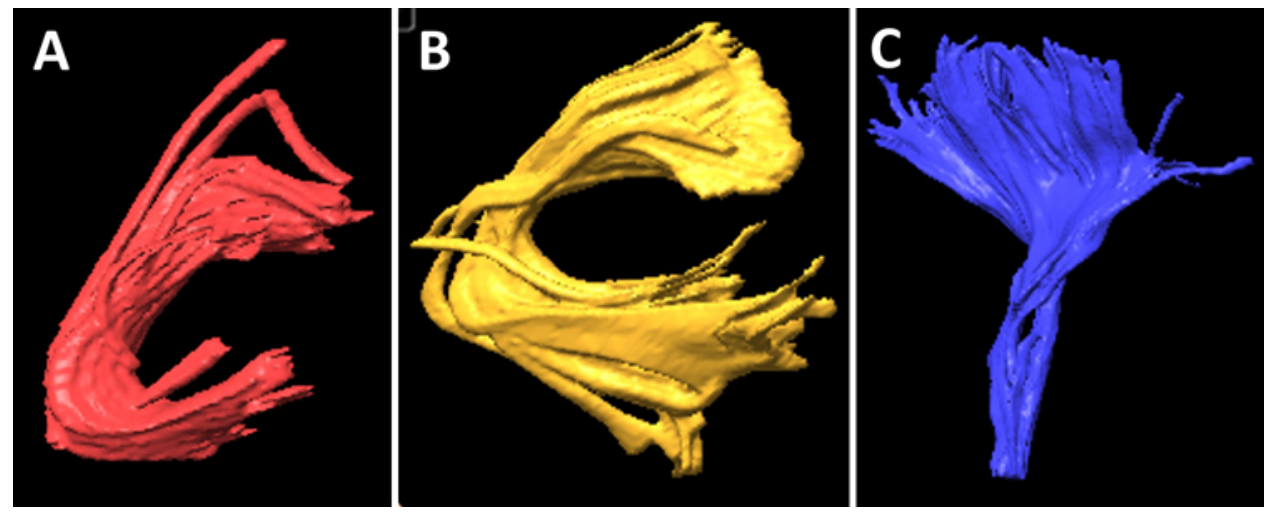

FIG. 1. Volumetric reconstruction of studied tracts: arcuate fasciculus (A), uncinate fasciculus (B), and internal capsule (C). Figure is available in color online only.

In all cases, we obtained the values of FA, number of fibers, and volume $\left(\mathrm{cm}^{3}\right)$ and length $(\mathrm{mm})$ of both fascicles (Figs. 1-3). These values were obtained through the iPlan Cranial software, where once the fiber bundle is created through the ROIs previously described, the software analyzes the presence or absence of fibers in each voxel, and then voxels are added to the final volume in those cases where there are fibers in the voxel. Similarly, the number of fibers is a relative estimation of fibers passing through the predetermined ROIs.

\section{Statistical Analysis}

SPSS (version 21.0, IBM Corp.) was used for statistical analysis. Kolmogorov-Smirnov tests were performed to assess the normality of the variables studied, and therefore the Student t-test was performed for the analysis. Measures of central tendency and dispersion are expressed as mean and variance $\left(\mathrm{S}^{2}\right)$. We also performed a linear discriminant analysis to determine if a combination of some variables could correctly predict language lateralization of the patients.

\section{Results}

Ten patients with temporal lobe epilepsy were included in our analysis; 5 were male and 5 were female. In 2 cases, the etiology of the epilepsy was related to gliomas; one was a ganglioglioma, and the other a grade II oligodendroglioma. The rest of the patients had idiopathic epilepsy. The mean age of patients was 39.4 years $\left(\mathrm{S}^{2} 121.93\right)$, and all patients had complex partial seizures, except for 1 patient who presented with tonic-clonic seizures. Mean seizure frequency was 8 seizures per month (range 3-16 seizures per month). Median preoperative Engel class was 3 (range 3-4). There were no postoperative neurological deficits and median Engel postoperative class was 1 (range $0-2$ ) at last follow-up.

The handedness distribution of the study population was 4 left-handed patients and 6 right-handed patients (Table 1). According to the Wada test, hemispheric dominance was right in 2 patients (one of them left-handed and one right-handed), and 6 patients had left hemispheric dominance (4 patients were right-handed and 2 left-hand- ed). In 2 cases, the Wada test showed bilateral hemispheric dominance, in a left-handed patient and a right-handed patient. Seizure focus was right in 6 patients, 3 of them left-handed and 3 right-handed; in the other 4 patients the seizure focus was left, in 1 left-handed and 3 right-handed patients.

After image acquisition of tracts as previously described, we compared the previously described variables. First, we found that mean FA of the arcuate fasciculus in the dominant hemisphere was $0.369\left(\mathrm{~S}^{2} 0.001\right)$, whereas it was $0.329\left(\mathrm{~S}^{2} 0.002\right)$ in the nondominant hemisphere $(\mathrm{p}=$ 0.049; Table 2). However, we did not find any significant difference in the FA of the uncinate fasciculus between hemispheres. Similarly, the number of fibers in the arcuate fasciculus was greater in the dominant hemisphere than in the nondominant side (881.5 [ $\left.\mathrm{S}^{2} 242524.9\right]$ vs 305.4 [ $\mathrm{S}^{2}$ 40608.0], $\mathrm{p}=0.003$ ). Moreover, we could not find any differences in the number of fibers in either uncinate fasciculus. When we compared the length of fibers in both tracts, we only found significant differences between the uncinate fasciculi (74.4 [S $\mathrm{S}^{2}$ 438.7] vs $50.1 \mathrm{~mm}$ [S $\mathrm{S}^{2}$ 908.7], p $=0.05)$, and not the arcuate fasciculi.

In both cases, the volume of the arcuate fasciculus and uncinate fasciculus bundles in the dominant hemisphere were significantly larger than in the nondominant side. Mean volume in the dominant arcuate fasciculus was $12.12\left(\mathrm{~S}^{2} 17.7\right) \mathrm{cm}^{3}$, and $6.48\left(\mathrm{~S}^{2} 11.7\right) \mathrm{cm}^{3}$ in the nondominant hemisphere $(\mathrm{p}=0.004)$. The uncinate fasciculus mean volume of the dominant hemisphere was $8.41\left(\mathrm{~S}^{2}\right.$ 19.6) $\mathrm{cm}^{3}$, versus $4.16\left(\mathrm{~S}^{2} 7.0\right) \mathrm{cm}^{3}$ in the nondominant side $(\mathrm{p}=0.018)$.

When we performed all these comparisons, we also compared the internal capsule bundle in each patient as a control. In these cases, there was no difference in any of the analyzed variables (Table 2).

We also separately analyzed those patients who had hemispheric dominance ipsilateral to the epilepsy focus, to evaluate if this characteristic could modify the previously found results. However, in this subgroup of cases, we still found that in the arcuate fasciculus the FA $\left(0.37\left[\mathrm{~S}^{2}\right.\right.$ $0.0003]$ vs 0.30 [ $\left.\left.\mathrm{S}^{2} 0.003\right], \mathrm{p}=0.03\right)$ number of fibers $(1142$ [ $\left.\mathrm{S}^{2} 299576.2\right]$ vs 315 [ $\left.\left.\mathrm{S}^{2} 48604.3\right], \mathrm{p}=0.014\right)$ and volume $\left(12.58 \mathrm{~cm}^{3}\left[\mathrm{~S}^{2} 19.9\right]\right.$ vs $\left.5.8 \mathrm{~cm}^{3}\left[\mathrm{~S}^{2} 14.84\right], \mathrm{p}=0.035\right)$ had 

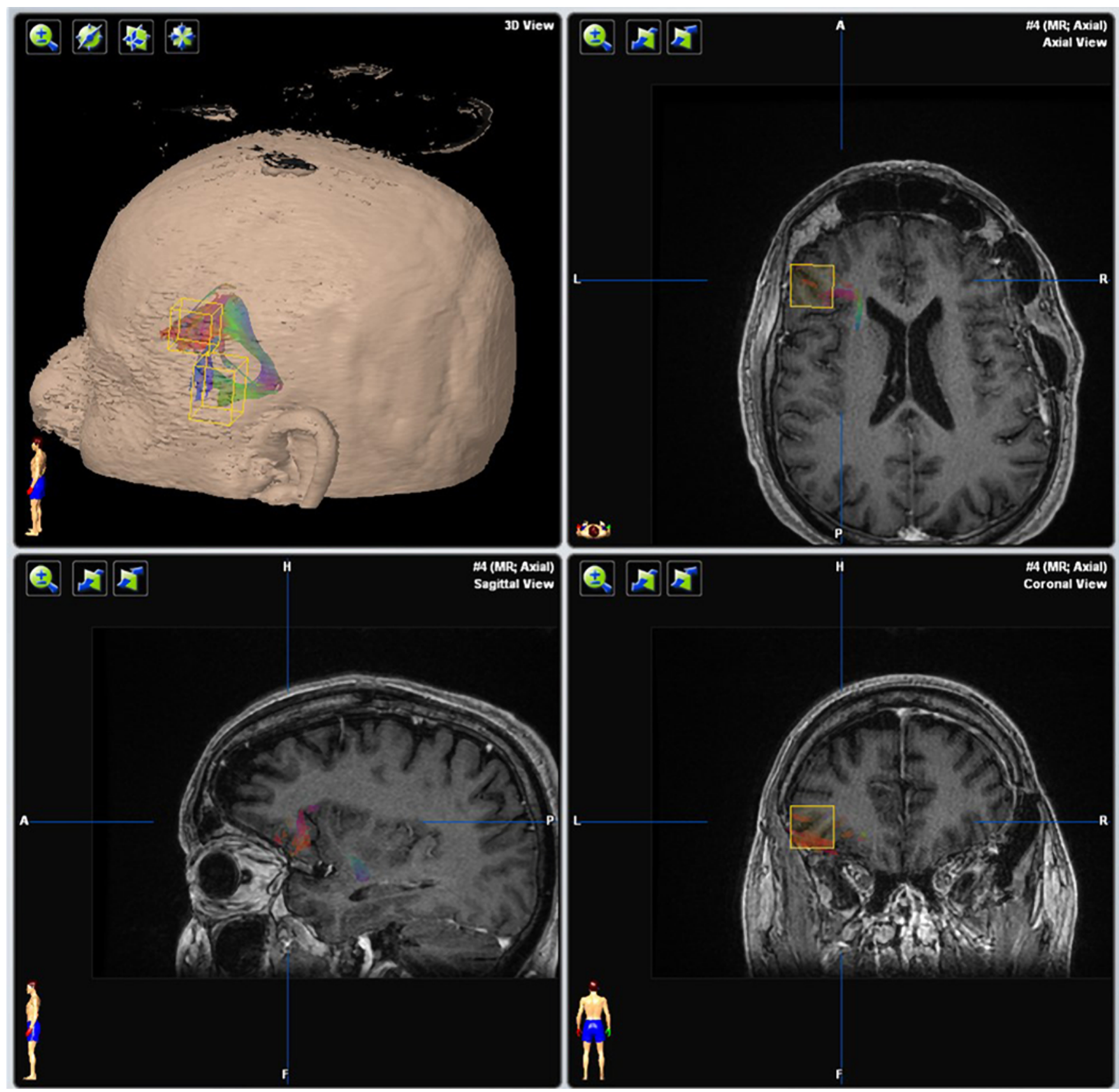

FIG. 2. DTI fiber tracking. ROI placement (yellow box) in the dominant uncinate fasciculus. Figure is available in color online only.

significantly higher values in the dominant hemisphere than in the nondominant side (Table 3).

We created a model through a linear discriminant analysis including FA, volume, and number of fibers of the arcuate fasciculus. In this case, the model was able to correctly predict $80 \%$ of the patients, with a canonical correlation of 0.660 (Wilks' lambda $=0.565, \mathrm{p}=0.024$ ). Standardized canonical discriminant coefficients showed that the best discriminant variable was the number of fibers (0.591), followed by volume (0.351), and FA (0.250; Fig. 4). The combination of these variables with the proposed model had a specificity of $90 \%$ and a sensitivity of $70 \%$ (Table 4).

\section{Discussion}

To date, the gold standard method for localizing language function remains the Wada test, a costly and invasive technique that can lead to complications in $10.9 \%$ of cases, such as encephalopathy (7.2\%), seizures (1.2\%), stroke $(0.6 \%)$, or carotid artery dissection, among others. ${ }^{29}$ To avoid the need to perform such a test, there has been an 


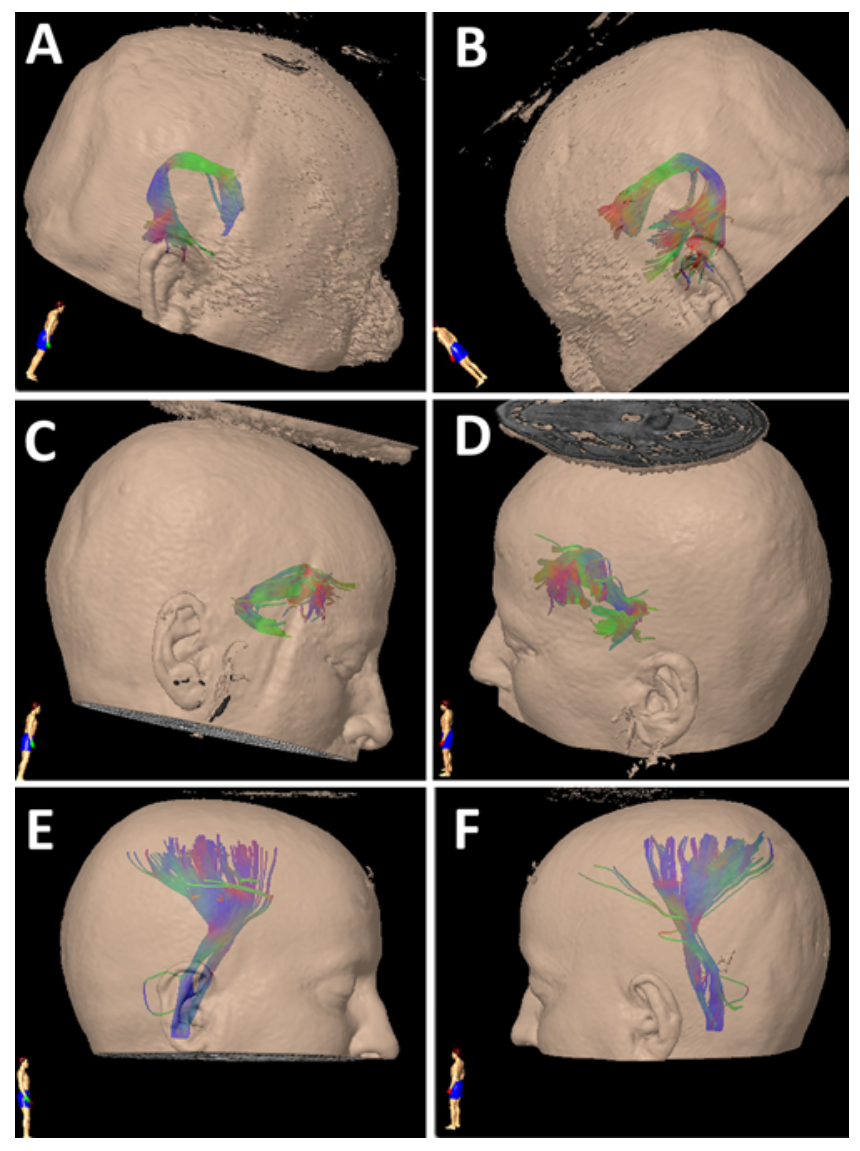

FIG. 3. DTI fiber tracking of an example case comparing the dominant (right column) and nondominant (left column) side: arcuate fasciculus (A and $B$ ), uncinate fasciculus ( $C$ and $D)$, and internal capsule ( $E$ and $F)$. Figure is available in color online only.

increasing interest in the study of fMRI and DTI to determine language location, as they are both noninvasive tests. All these studies have been conducted through analysis of the mean diffusivity, defined as the mobility of water molecules in a voxel, and FA, which denotes the directionality of the fibers. ${ }^{18}$

\section{TABLE 1. Patient characteristics}

\begin{tabular}{rrrrrc}
\hline Case No. & Handedness & Age & Sex & Seizure Focus & Wada Test \\
\hline 1 & $\mathrm{Rt}$ & 51 & $\mathrm{M}$ & $\mathrm{Rt}$ & $\mathrm{Lt}$ \\
\hline 2 & $\mathrm{Rt}$ & 21 & $\mathrm{M}$ & $\mathrm{Rt}$ & $\mathrm{Lt}$ \\
\hline 3 & $\mathrm{Rt}$ & 40 & $\mathrm{~F}$ & $\mathrm{Lt}$ & $\mathrm{Lt}$ \\
\hline 4 & $\mathrm{Lt}$ & 47 & $\mathrm{~F}$ & $\mathrm{Rt}$ & $\mathrm{Rt}$ \\
\hline 5 & $\mathrm{Lt}$ & 51 & $\mathrm{~F}$ & $\mathrm{Rt}$ & $\mathrm{Lt}$ \\
\hline 6 & $\mathrm{Lt}$ & 42 & $\mathrm{~F}$ & $\mathrm{Lt}$ & $\mathrm{Lt}$ \\
\hline 7 & $\mathrm{Rt}$ & 34 & $\mathrm{~F}$ & $\mathrm{Lt}$ & $\mathrm{Lt}$ \\
\hline 8 & $\mathrm{Lt}$ & 35 & $\mathrm{M}$ & $\mathrm{Rt}$ & Bilat \\
\hline 9 & $\mathrm{Rt}$ & 22 & $\mathrm{M}$ & $\mathrm{Rt}$ & $\mathrm{Rt}$ \\
\hline 10 & $\mathrm{Rt}$ & 51 & $\mathrm{M}$ & $\mathrm{Lt}$ & Bilat \\
\hline
\end{tabular}

TABLE 2. Mean values of DTI parameters comparing both hemispheres

\begin{tabular}{cccc}
\hline \multirow{2}{*}{ DTI Parameter } & \multicolumn{2}{c}{ Hemisphere } & $\begin{array}{c}p \\
\text { Value }\end{array}$ \\
\cline { 2 - 3 } & Dominant & Nondominant & \\
\hline FA & & & \\
\hline Arcuate fasciculus & 0.369 & 0.329 & 0.049 \\
\hline Uncinate fasciculus & 0.31 & 0.25 & 0.12 \\
\hline Internal capsule & 0.44 & 0.42 & 0.58 \\
\hline No. of fibers & & & \\
\hline Arcuate fasciculus & 881.5 & 305.4 & 0.003 \\
\hline Uncinate fasciculus & 745.2 & 280.5 & 0.13 \\
\hline Internal capsule & 1485 & 1500 & 0.98 \\
\hline Length of fibers (mm) & & & \\
\hline Arcuate fasciculus & 87.2 & 83.4 & 0.76 \\
\hline Uncinate fasciculus & 74.4 & 50.1 & 0.05 \\
\hline Internal capsule & 133 & 136 & 0.58 \\
\hline Volume (cm ${ }^{3}$ ) & & & \\
\hline Arcuate fasciculus & 12.2 & 6.5 & 0.004 \\
\hline Uncinate fasciculus & 8.4 & 4.1 & $\mathbf{0 . 0 1 8}$ \\
\hline Internal capsule & 25.8 & 26.8 & 0.81 \\
\hline Bolface type indicates sticann
\end{tabular}

Boldface type indicates statistical significance.

Different studies have tested whether fiber tracking with DTI is useful to describe language dominance, as compared to fMRI, both in healthy volunteers and in patients with epilepsy. These studies have demonstrated that there is a lateralization with higher parameters in the dominant hemisphere of healthy volunteers, mainly consisting of higher FA values in the arcuate fasciculus and uncinate fasciculus, ${ }^{20,21}$ but also present in epilepsy patients $^{9}$ in relation to other anomalies such as executive and verbal memory deficits. ${ }^{18}$ These differences appear to correlate with a higher connectivity between Broca's and Wernicke's areas in the dominant hemisphere, acquired through human evolution as compared to monkeys. ${ }^{30,31} \mathrm{An}$ other concern that could be addressed with the Wada test is its capability to predict memory impairment. However, some previous studies have demonstrated that neuropsychological tests and MRI volumetry can predict changes in verbal and visual memory after epilepsy surgery, making use of invasive techniques such as the Wada test pointless. ${ }^{32}$ Moreover, the Wada test is not an adequate test for

TABLE 3. Comparisons of mean volume of the arcuate fasciculus between hemispheres in patients with seizure focus on the dominant side

\begin{tabular}{lccc}
\hline Arcuate Fasciculus & Dominant & Nondominant & $p$ Value \\
\hline FA & 0.37 & 0.3 & $\mathbf{0 . 0 3}$ \\
\hline No. of fibers & 1142 & 315 & $\mathbf{0 . 0 1 4}$ \\
\hline Length of fibers $(\mathrm{mm})$ & 79.4 & 73.2 & 0.72 \\
\hline Volume $\left(\mathrm{cm}^{3}\right)$ & 12.6 & 5.8 & $\mathbf{0 . 0 3}$ \\
\hline
\end{tabular}

Boldface type indicates statistical significance. 

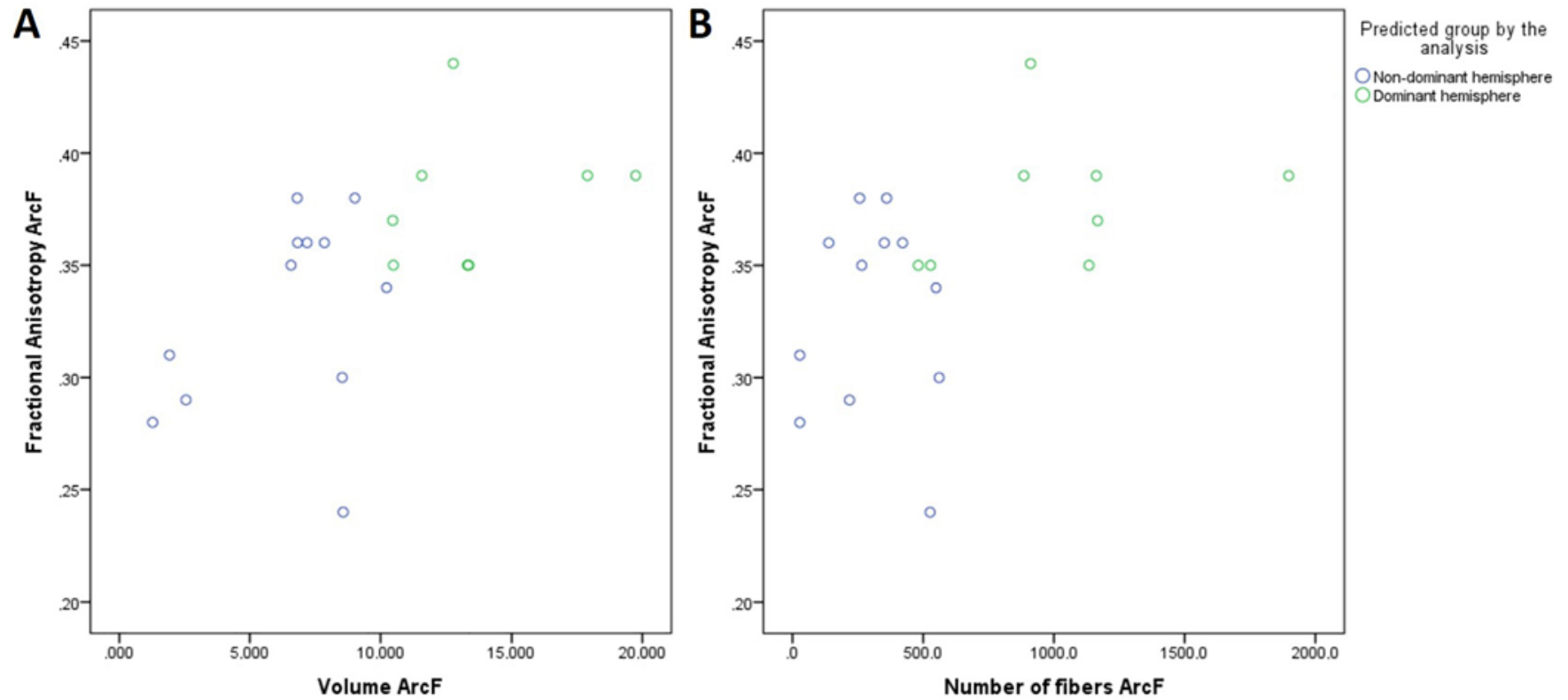

FIG. 4. Scatterplot of the linear discriminant analysis model. A: Discriminant analysis using volume and FA of the arcuate fasciculus (ArCF). B: Discriminant analysis using number of fibers and FA of the arcuate fasciculus. Figure is available in color online only.

memory impairment as other brain areas are implicated in its performance,,$^{33}$ and their results could be inconsistent, ${ }^{34}$ making the Wada test a better diagnostic tool for language compared to memory in predicting postsurgical memory decline. ${ }^{35}$

Nevertheless, there is controversy regarding the correlation between the Wada test and fMRI. In those patients with an atypical language hemispheric dominance, the sensitivity of this test has been described as high as $83.5 \%$ (95\% confidence interval [CI] 80.2\%-86.7\%) and its specificity as high as $88.1 \%$ (95\% CI $87 \%-89.2 \%) .{ }^{23}$ However, other studies have demonstrated that fMRI has no high specificity $(50 \%-70 \%)$ in localizing language areas, because there are other areas that could be involved in language processing. ${ }^{36}$ In other series, the mismatch between the Wada test and fMRI has been described as between $3 \%$ and $25 \% .{ }^{37}$

Although there are an increasing number of articles trying to establish the relation between the Wada test and fMRI, there is a lack of studies analyzing the direct relation between MR DTI and the Wada test. Ellmore and colleagues $^{24}$ studied 23 patients with pharmacoresistant

TABLE 4. Group prediction distribution by linear discrimination analysis

\begin{tabular}{lccc}
\hline & \multicolumn{2}{c}{ Predicted Group by the Analysis } & \\
\cline { 2 - 4 } Wada Test & $\begin{array}{c}\text { Nondominant } \\
\text { Hemisphere }\end{array}$ & $\begin{array}{c}\text { Dominant } \\
\text { Hemisphere }\end{array}$ & Total \\
\hline Nondominant hemisphere & 9 & 1 & 10 \\
\hline Dominant hemisphere & 3 & 7 & 10 \\
\hline Total & 12 & 8 & 20 \\
\hline
\end{tabular}

epilepsy and compared FA and the laterality index of FA obtained through DTI tractography, with the data obtained from the Wada test and fMRI for the arcuate fasciculus, uncinate fasciculus, and inferior longitudinal fasciculus. Results showed that dominant hemispheres had a higher FA value in the arcuate fasciculus bundle, but the laterality index had a lower correlation with the Wada test than fMRI (19/23 in FA laterality index vs 20/23 fMRI). The FA laterality index in this study showed similar results to those obtained in our linear discriminant analysis model. However, these authors proposed a combination of these studies to obtain a better correlation. In this case, binary logistic regression combining DTI, fMRI, and handedness was able to predict correct language location in 22 of 23 patients. Similarly, Tiwari et al..$^{36}$ also compared FA and volume values of the arcuate fasciculus with results from the Wada test. These authors also found that there was a correlation between the Wada test and a higher volume in the arcuate fasciculus $(p=0.02)$, and a trend toward significance with FA values $(\mathrm{p}=0.07)$. These results are similar to those obtained in our study. Finally, the largest study published to date about this topic analyzed 24 patients and compared results from DTI of the arcuate fasciculus with the Wada test. ${ }^{38}$ In this case, the arcuate fasciculus was divided in the frontotemporal tract, the bundle that included those fibers approaching an additional ROI in the planum temporale; and the frontoparietal tract, which did not reach that ROI. Results showed that the frontotemporal tract had more fibers, were greater in length, and the bundle was greater in volume in the dominant hemisphere, while the frontoparietal tract and FA did not show these differences. These authors also showed that there was a tendency to find higher values of these parameters in the frontotemporal tract in the dominant hemisphere, even though the pathology was located in that hemisphere. These conclusions 
are consistent with the results obtained in our study, in which we showed that FA, volume, and number of fibers of the arcuate fasciculus were greater in the dominant hemisphere, and volume and length of fibers in the uncinate fasciculus were also higher in the dominant hemisphere. Finally, in our series we found that in those patients in whom the seizure focus was located in the dominant hemisphere, values of FA, number of fibers, and volume of the arcuate fasciculus bundle were still significant, and could still be useful for establishing hemisphere dominance in this type of patient.

However, some limitations in our study should be noted, primarily the small number of patients in the study and that their heterogeneity could interfere with a correlation to larger groups. The conclusions and new information we have described are interesting and could lead to a better understanding in the relation between the Wada test and DTI, but we should still consider this cohort as a pilot study. Nevertheless, the lack of current information in the relation between the Wada test and DTI that we have previously described, and the fact that our results agree with previously published data, make them worth studying in the future.

\section{Conclusions}

Recent studies have stated that DTI could help determine language dominance in patients. However, we believe it is very important to remember that, before we can assume that DTI could replace an invasive technique such as the Wada test, we have to get a better correlation between DTI and the gold standard test for language location, meaning that DTI should be compared with the Wada test, and not compare it with fMRI. This topic has been little studied and more investigation should be performed, but some previous investigations and the present study make some favorable arguments that the dominant hemisphere could be detected, not only through the presence of higher DTI parameter values such as FA, volume, and number and length of fibers (mainly in the arcuate fasciculus), but also in other fiber bundles such as the uncinate fasciculus, and other tracts involved in language as technology evolves.

\section{References}

1. Chang EF, Raygor KP, Berger MS. Contemporary model of language organization: an overview for neurosurgeons. $J$ Neurosurg. 2015;122(2):250-261.

2. Kim CH, Chung CK, Koo BB, et al. Changes in language pathways in patients with temporal lobe epilepsy: diffusion tensor imaging analysis of the uncinate and arcuate fasciculi. World Neurosurg. 2011;75(3-4):509-516.

3. Lurito JT, Dzemidzic M. Determination of cerebral hemisphere language dominance with functional magnetic resonance imaging. Neuroimaging Clin N Am. 2001;11(2): $355-363$, x.

4. Woods RP, Dodrill CB, Ojemann GA. Brain injury, handedness, and speech lateralization in a series of amobarbital studies. Ann Neurol. 1988;23(5):510-518.

5. Helmstaedter C, Kurthen M, Linke DB, Elger CE. Patterns of language dominance in focal left and right hemisphere epilepsies: relation to MRI findings, EEG, sex, and age at onset of epilepsy. Brain Cogn. 1997;33(2):135-150.
6. Kurthen M, Helmstaedter C, Linke DB, et al. Quantitative and qualitative evaluation of patterns of cerebral language dominance. An amobarbital study. Brain Lang. 1994;46(4): $536-564$.

7. Staudt M, Lidzba K, Grodd W, et al. Right-hemispheric organization of language following early left-sided brain lesions: functional MRI topography. Neuroimage. 2002;16(4): 954-967.

8. Thivard L, Hombrouck J, du Montcel ST, et al. Productive and perceptive language reorganization in temporal lobe epilepsy. Neuroimage. 2005;24(3):841-851.

9. Rodrigo S, Oppenheim C, Chassoux F, et al. Language lateralization in temporal lobe epilepsy using functional MRI and probabilistic tractography. Epilepsia. 2008;49(8):1367-1376.

10. Bahn MM, Lin W, Silbergeld DL, et al. Localization of language cortices by functional MR imaging compared with intracarotid amobarbital hemispheric sedation. AJR Am J Roentgenol. 1997;169(2):575-579.

11. Bonilha L, Keller SS. Quantitative MRI in refractory temporal lobe epilepsy: relationship with surgical outcomes. Quant Imaging Med Surg. 2015;5(2):204-224.

12. Pastor J, Ortega GJ, Herrera-Peco I, et al. Differential contribution of preoperatory studies to diagnosis in temporal lobe epilepsy surgery. Article in Spanish. Rev Neurol. 2010;51(7): 393-402.

13. Sola RG, Hernando-Requejo V, Pastor J, et al. Pharmacoresistant temporal-lobe epilepsy. Exploration with foramen ovale electrodes and surgical outcomes. Article in Spanish. Rev Neurol. 2005;41(1):4-16.

14. García-Pallero MÁ, Torres CV, Manzanares-Soler R, et al. The role of diffusion tensor imaging in the pre-surgical study of temporal lobe epilepsy. Article in Spanish. Rev Neurol. 2016;63(12):537-542.

15. García-Pallero MA, Hodaie M, Zhong J, et al. Prediction of laterality in temporal lobe epilepsy using white matter diffusion metrics. World Neurosurg. 2019;128:e700-e708.

16. Assaf Y, Pasternak O. Diffusion tensor imaging (DTI)-based white matter mapping in brain research: a review. $\mathrm{J} \mathrm{Mol} \mathrm{Neu-}$ rosci. 2008;34(1):51-61.

17. Concha L, Kim H, Bernasconi A, et al. Spatial patterns of water diffusion along white matter tracts in temporal lobe epilepsy. Neurology. 2012;79(5):455-462.

18. McDonald CR, Ahmadi ME, Hagler DJ, et al. Diffusion tensor imaging correlates of memory and language impairments in temporal lobe epilepsy. Neurology. 2008;71(23):1869-1876.

19. Powell HWR, Parker GJM, Alexander DC, et al. Abnormalities of language networks in temporal lobe epilepsy. Neuroimage. 2007;36(1):209-221.

20. Silva G, Citterio A. Hemispheric asymmetries in dorsal language pathway white-matter tracts: a magnetic resonance imaging tractography and functional magnetic resonance imaging study. Neuroradiol J. 2017;30(5):470-476.

21. Vassal F, Schneider F, Boutet C, et al. Combined DTI tractography and functional MRI study of the language connectome in healthy volunteers: extensive mapping of white matter fascicles and cortical activations. PLoS One. 2016;11(3): $\mathrm{e} 0152614$.

22. Vernooij MW, Smits M, Wielopolski PA, et al. Fiber density asymmetry of the arcuate fasciculus in relation to functional hemispheric language lateralization in both right- and lefthanded healthy subjects: a combined fMRI and DTI study. Neuroimage. 2007;35(3):1064-1076.

23. Dym RJ, Burns J, Freeman K, Lipton ML. Is functional MR imaging assessment of hemispheric language dominance as good as the Wada test?: a meta-analysis. Radiology. 2011; 261(2):446-455.

24. Ellmore TM, Beauchamp MS, Breier JI, et al. Temporal lobe white matter asymmetry and language laterality in epilepsy patients. Neuroimage. 2010;49(3):2033-2044. 
25. Jordán González J, Prince López J. Uso de propofol para la determinación de elocuencia en las embolizaciones de las malformaciones arteriovenosas cerebrales. Investig Medicoquir. 2010;2(2):10-14.

26. Catani M, Thiebaut de Schotten M. A diffusion tensor imaging tractography atlas for virtual in vivo dissections. Cortex. 2008;44(8):1105-1132.

27. Rodrigo S, Oppenheim C, Chassoux F, et al. Uncinate fasciculus fiber tracking in mesial temporal lobe epilepsy. Initial findings. Eur Radiol. 2007;17(7):1663-1668.

28. Pustina D, Avants B, Sperling M, et al. Predicting the laterality of temporal lobe epilepsy from PET, MRI, and DTI: a multimodal study. Neuroimage Clin. 2015;9:20-31.

29. Loddenkemper T, Morris HH, Möddel G. Complications during the Wada test. Epilepsy Behav. 2008;13(3):551-553.

30. Catani M, Allin MPG, Husain M, et al. Symmetries in human brain language pathways correlate with verbal recall. Proc Natl Acad Sci U S A. 2007;104(43):17163-17168.

31. Aboitiz F, García V R. The evolutionary origin of the language areas in the human brain. A neuroanatomical perspective. Brain Res Brain Res Rev. 1997;25(3):381-396.

32. Lineweaver TT, Morris HH, Naugle RI, et al. Evaluating the contributions of state-of-the-art assessment techniques to predicting memory outcome after unilateral anterior temporal lobectomy. Epilepsia. 2006;47(11):1895-1903.

33. Ojemann JG, Kelley WM. The frontal lobe role in memory: a review of convergent evidence and implications for the Wada memory test. Epilepsy Behav. 2002;3(4):309-315.

34. Loddenkemper T, Morris HH, Lineweaver TT, Kellinghaus C. Repeated intracarotid amobarbital tests. Epilepsia. 2007; 48(3):553-558.

35. Schmid E, Thomschewski A, Taylor A, et al. Diagnostic accuracy of functional magnetic resonance imaging, Wada test, magnetoencephalography, and functional transcranial Doppler sonography for memory and language outcome after epilepsy surgery: a systematic review. Epilepsia. 2018;59(12): 2305-2317.

36. Tiwari VN, Jeong JW, Asano E, et al. A sensitive diffusion tensor imaging quantification method to detect language laterality in children: correlation with the Wada test. J Child Neurol. 2011;26(12):1516-1521.

37. Woermann FG, Jokeit H, Luerding R, et al. Language lateralization by Wada test and fMRI in 100 patients with epilepsy. Neurology. 2003;61(5):699-701.
38. Matsumoto R, Okada T, Mikuni N, et al. Hemispheric asymmetry of the arcuate fasciculus: a preliminary diffusion tensor tractography study in patients with unilateral language dominance defined by Wada test. J Neurol. 2008;255(11): 1703-1711.

\section{Disclosures}

The authors report no conflict of interest concerning the materials or methods used in this study or the findings specified in this paper.

\section{Author Contributions}

Conception and design: Delgado-Fernández, García-Pallero, Manzanares-Soler, Blasco, Frade-Porto, Pulido, Sola, Torres. Acquisition of data: Delgado-Fernández, Manzanares-Soler, Martín-Plasencia, Blasco, Frade-Porto, Sola. Analysis and interpretation of data: Delgado-Fernández, García-Pallero, Blasco, Frade-Porto, Pulido, Sola, Torres. Drafting the article: DelgadoFernández, Torres. Critically revising the article: García-Pallero, Manzanares-Soler, Martín-Plasencia, Blasco, Frade-Porto, NavasGarcía, Pulido, Sola, Torres. Reviewed submitted version of manuscript: Delgado-Fernández, Blasco, Pulido, Torres. Approved the final version of the manuscript on behalf of all authors: Delgado-Fernández. Statistical analysis: Delgado-Fernández. Administrative/technical/material support: Manzanares-Soler, Pulido. Study supervision: García-Pallero, Pulido, Sola, Torres.

\section{Supplemental Information}

\section{Previous Presentations}

This work was previously presented orally at the Annual Meeting of the Spanish Society of Neurosurgery, May 16-18, 2018, in Toledo, Spain, and at the 18th Biennial Meeting of the World Society for Stereotactic and Functional Neurosurgery, June 24-27, 2019, in New York, New York.

\section{Correspondence}

Juan Delgado-Fernández: University Hospital 12 de Octubre, Madrid,Spain. juan.delgado.fdez@gmail.com. 